\title{
Effect of calcium on porcine ICSI embryos expressing EGFP is related to activation of ooplasmic DNase I
}

\author{
Shuaishuai WU*, Heng CHEN", Yingzheng WANG, Hui GAO, Shenming ZENG (ه) \\ Laboratory of Animal Embryonic Biotechnology, College of Animal Science and Technology, \\ China Agricultural University, Beijing 100193, China
}

\begin{abstract}
Several reliable methods to produce transgenic animals use the male genome. After penetration into oocytes, sperm DNA undergoes dramatic conformational changes that might represent an opportunity for exogenous DNA to integrate into the zygote genome. A nuclease, DNase I, with $\mathrm{Ca}^{2+} / \mathrm{Mg}^{2+}$ dependent activity and $\mathrm{Zn}^{2+}$ inhibition, is one of the enzymes responsible for sperm DNA remodeling. To date, the effect of different calcium concentrations in manipulation media on porcine intracytoplasmic sperm injection has not been fully investigated. The present study was conducted to examine the effect of calcium in the surrounding media, and we found that the number of embryos expressing green fluorescent protein (EGFP) was increased in media containing $\mathrm{Ca}^{2+}$. However, the number did not change over $\mathrm{Ca}^{2+}$ concentrations from 2 to $8 \mathrm{mmol} \cdot \mathrm{L}^{-1}(P>0.05)$. Moreover, free $\mathrm{Ca}^{2+}$ concentrations in the media were found to affect the efficiency which is porcine intracytoplasmic sperm injection (ICSI) embryos expressing EGFP protein, which was related to the activation of ooplasmic DNase I. These findings reveal a mechanism and pathway involving EGFP expression in ICSI embryos.
\end{abstract}

Keywords porcine intracytoplasmic sperm injection (ICSI), calcium, DNase I, GFP, porcine

\section{Introduction}

Transgenesis represents an important tool in basic research as well as in livestock production. Several reliable methods to produce transgenic animals use the male genome for exogenous DNA integration. Male pronuclear injection is currently the most frequently used method to generate transgenic animals. Porcine intracytoplasmic sperm injec-

Received January 8, 2015; accepted March 24, 2015

Correspondence: zengsm@cau.edu.cn

${ }^{*}$ These authors contribute equally to the work tion (ICSI) to produce transgenic pigs has become indispensable to biomedical research. However, the rate of successful incorporation of the exogenous genes into the host genome is extremely low in animals ${ }^{[1]}$. Moreover, exogenous DNA injection into the ooplasm does not result in transgenic progeny ${ }^{[2]}$.

Factors that have been reported to influence the outcome of transgenesis in porcine embryos through ICSI include temperature during micromanipulation, exogenous DNA concentrations, plasmid constructs ${ }^{[3]}$ and DNase I treatment $^{[4]}$.

Szczygiel et al. ${ }^{[5]}$ found that $\mathrm{Ca}^{2+}$ chelators (EDTA or EGTA) in the suspensions of sperm cell and exogenous DNA could decrease transgenesis and affect the degree of DNA integration into chromosomes, and that this was related to a $\mathrm{Ca}^{2+} / \mathrm{Mg}^{2+}$-dependent enzyme in the oocyte. A $\mathrm{Ca}^{2+} / \mathrm{Mg}^{2+}$-dependent DNase I in pig MII oocytes has been documented which could significantly protect linearized exogenous DNA when microinjected ${ }^{[6]}$.

The influence of $\mathrm{Ca}^{2+}$ in ICSI manipulation medium on the efficiency of transgene expression has not previously been investigated. So this study was designed to explore whether $\mathrm{Ca}^{2+}$ concentrations in manipulation medium could affect the efficiency of porcine embryos expressing enhanced green fluorescent protein (EGFP) by ICSI, as well as possible causes contributing to this effect.

\section{Materials and methods}

All chemicals used in this study were purchased from Sigma Chemicals (St. Louis, MO, USA) unless otherwise specified.

\subsection{Source of the gametes}

\subsubsection{Porcine oocytes}

Ovaries were obtained from white crossbred gilts at a local 
slaughterhouse and transferred to the laboratory within $2 \mathrm{~h}$ in D-PBS containing $75 \mathrm{mg} \cdot \mathrm{L}^{-1}$ penicillin and $50 \mathrm{mg} \cdot \mathrm{L}^{-1}$ streptomycin at $35^{\circ} \mathrm{C}$. The ovaries were washed twice in the same solution on arriving at the laboratory.

The cumulus oocyte complexes were aspirated from follicles $(2-6 \mathrm{~mm}$ in diameter) using a $10 \mathrm{~mL}$ syringe with an 18 -gauge needle. The aspirate was pooled into $15 \mathrm{~mL}$ plastic centrifuge tubes. After settlement, the supernatant was discarded and the sediment washed twice in TLHepes $^{[2]}$. Oocytes with even cytoplasm and tight cumulus cell layers were selected and matured in a Petri dish in $100 \mu \mathrm{L}$ droplets in $5 \% \mathrm{CO}_{2}$ in air at $100 \%$ humidity and $38.5^{\circ} \mathrm{C}$ for $44 \mathrm{~h}$. The maturation medium was TCM199 (with Earles' salts; Gibco, Grand Island, NY, USA) supplemented with $10 \%$ porcine follicular fluid, $10 \mathrm{IU} \cdot \mathrm{mL}^{-1}$ hCG (Chorulon, Intervet Australia Pty Limited, Victoria, Australia), $10 \mathrm{IU} \cdot \mathrm{mL}^{-1} \mathrm{eCG}$ (Folligon, Intervet Australia Pty Limited, Victoria, Australia), $10 \mathrm{ng} \cdot \mathrm{mL}^{-1}$ EGF, $0.60 \mathrm{mmol} \cdot \mathrm{L}^{-1}$ cysteine, $75 \mathrm{mg} \cdot \mathrm{L}^{-1}$ penicillin and $50 \mathrm{mg} \cdot \mathrm{L}^{-1}$ streptomycin.

\subsubsection{Sperm preparation}

The semen from two Large Yorkshire boars was collected by the gloved-hand method ${ }^{[2]}$ and mixed together. The semen was then washed three times and diluted to $1 \times 10^{6} \mathrm{~mol} \cdot \mathrm{L}^{-1}$ spermatozoa in TL-Hepes solution containing $0.3 \%$ BSA before freezing in liquid nitrogen without any cryoprotectant in $0.25 \mathrm{~mL}$ straws (IVM, L'Aigle, France). Before ICSI, one straw of the semen was thawed in a $37^{\circ} \mathrm{C}$ water bath for $30 \mathrm{~s}$. Aliquots $(30 \mu \mathrm{L})$ of the semen were then washed twice with $1 \mathrm{~mL}$ TL-Hepes and the sperm harvested by centrifugation at $1000 \times g$ for $5 \mathrm{~min}$. The sperm was then treated according to the experimental designs.

\section{2 pEGFP-N1 plasmid DNA}

The pEGFP-N1 plasmid (Clontech, Mountain View, CA, USA) was $4.7 \mathrm{~kb}$ in length and encoded the GFP mut 1 variant that could be expressed in mammalian cells under the control of the CMV promoter was used. The plasmid was first amplified in E. coli and then purified, and the plasmid expressed EGFP had an excitation peak at $488 \mathrm{~nm}$ and maximal emission peak at $507 \mathrm{~nm}$. One part of the circular plasmid DNA was restricted with Ase I (Hyclone USA). The DNA was stored at a concentration of $0.5 \mu \mathrm{g} \cdot \mathrm{mL}^{-1}$ in Tris-EDTA solution before use.

\subsection{Micromanipulation techniques}

ICSI was carried out at $37^{\circ} \mathrm{C}$ in microdrops of Hepes buffered Sperm Preparation Medium (SPM; Medicult, Copenhagen, Denmark) under embryo culture-tested light mineral oil (Sigma, La Verpillire, France) equilibrated with
$5 \% \mathrm{CO}_{2}$ in air. Sperm and $0.05 \mu \mathrm{g} \cdot \mathrm{mL}^{-1} \mathrm{pEGFP}-\mathrm{N} 1 \mathrm{DNA}$ were incubated at $4^{\circ} \mathrm{C}$ for $1 \mathrm{~h}$. Then one spermatozoon was injected into the ooplasm of each oocyte with the use of an Olympus IMT- 2 inverted research microscope equipped with a Narishige MN 151 (Narishige Co., Tokyo, Japan) mechanical joystick manipulator (to control the holding pipette) and with a Narishige MO-202 remote-control hydraulic manipulator (to control the microinjection needle). Details of the preparation of micromanipulation instruments, sperm treatment and the microinjection technique were as previously published ${ }^{[7]}$. After sperm injection, the oocytes were stored in H199 until electroactivation. Control oocytes were sham-injected in the same way as oocytes subjected to ICSI except for the absence of sperm in the injected medium.

\subsection{Electrical stimulation}

The electro-activation solution contained $0.3 \mathrm{~mol} \cdot \mathrm{L}^{-1}$ mannitol, $0.05 \mathrm{mmol} \cdot \mathrm{L}^{-1} \quad \mathrm{CaCl}_{2}, 0.1 \mathrm{mmol} \cdot \mathrm{L}^{-1} \quad \mathrm{MgCl}_{2}$ and $0.1 \%$ BSA. The ICSI oocytes were washed three times in mannitol solution and transferred to an irradiation chamber (Fujira Industry Co. Ltd., Japan), which was filled with $1 \mathrm{~mL}$ of the electro-activation solution. The distance between the two electrodes in the chamber was $1.08 \mathrm{~mm}$ and oocytes were placed in this gap, then subjected to an activation pulse (DC $\left.120 \mathrm{~V} \cdot \mathrm{mm}^{-1}, 80 \mu \mathrm{s}\right)$ from an electric cell-fusion machine (Fujira Industry Co. Ltd., Japan).

\subsection{ICSI embryo changes and EGFP expression}

The ICSI oocytes were cultured in PZM- ${ }^{[8]}$ for $3 \mathrm{~h}$ (regardless of electro-stimulation), then treated in $2 \mathrm{~mm} 6-$ dymethylaminopurine for $6 \mathrm{~h}$. Then transferred again into PZM-3 at $39^{\circ} \mathrm{C}$ with $5 \% \mathrm{CO}_{2}$ in humidified air for 7 days. The development of ICSI embryos was observed 7 days after activation and the percentages of blastocyst formation were calculated. Then the ICSI embryos were checked directly in the culture dish under an inverted fluorescent microscope at $488 \mathrm{~nm}$ irradiation (IX70, Olympus, Japan) to determine EGFP expression. Green fluorescent embryos were considered positive embryos expressing $\mathrm{EGFP}^{[7]}$.

\subsection{Ooplasmic DNase I activity}

Ninety oocytes divided into two groups, one part was treated by electrical stimulation and the other part was used for the control. The oocytes were broken up by repeated pipetting. The supernatant after centrifugation was incubated with methyl green in the presence of $2 \mathrm{mmol} \cdot \mathrm{L}^{-1}$ $\mathrm{Mg}^{2+}$ and $2 \mathrm{mmol} \cdot \mathrm{L}^{-1} \mathrm{Ca}^{2+}$. Different concentrations of DNase I were incubated with DNA and methyl green and $488 \mathrm{~nm}$ absorbance measured. The DNase I concentration standard curve was used to calculate the values for treatment and control groups. 


\subsection{Statistical analysis}

More than 30 ICSI oocytes were used for each treatment. All dependent variables were analyzed for normality using the Wilks-Shapiro test (SAS Institute, Cary, NC, USA). Percentages were subjected to arcsine transformation prior to analysis and the transformed data were analyzed by one way ANOVA using the GLM procedure of SAS. Differences among treatment means were determined with Duncan's multiple-range test. Differences were considered significant at $P<0.05$. All data were expressed as mean \pm S.E.M.

\section{Results}

3.1 Effects of $\mathrm{Ca}^{2+}$ concentration on ICSI embryos development and EGFP expression with/without electrical activation

The results (Table 1) for the group without electrical activation demonstrated that the rates of cleavage varied with concentrations of calcium added to the media. The rate of cleavage in the $0 \mathrm{mmol} \cdot \mathrm{L}^{-1}$ group was significantly lower than for other groups $(P<0.05)$. Both rates in 4 and $6 \mathrm{mmol} \cdot \mathrm{L}^{-1}$ groups were significantly higher than other groups $(P<0.05)$, although there were no differences between them. The number of embryos expressing EGFP was significantly increased in the media containing $\mathrm{Ca}^{2+}$, whereas the number did not change with $\mathrm{Ca}^{2+}$ concentrations from 2 to $8 \mathrm{mmol} \cdot \mathrm{L}^{-1}(P>0.05)$. In contrast, the number of blastocysts was unaffected by the $\mathrm{Ca}^{2+}$ concentrations in the media $(P>0.05)$.

In the electrical activation group, cleavage and number of blastocyst in all the groups were not statistically different $(P>0.05)$. However, the number of embryos expressing EGFP was significantly affected by $\mathrm{Ca}^{2+}$ in the medium with electrical activation $(P<0.05)$.

\subsection{Effect of electro-activation on DNase I activity of oocytes}

For comparison, DNase I activities in porcine oocytes with electrical stimulation were measured (Fig. 1a), with electrical activated oocytes instead of the ICSI as the treatment group and no electrical activation as a control. Oocyte cytoplasm, methyl green and DNA were incubated and absorbance measured. The results showed that DNase I activity significantly increased after electro-activation $(P<0.05)$.

3.3 Effects of $\mathrm{Zn}^{2+}$ on ICSI embryos development and EGFP expression

$\mathrm{Zn}^{2+}$ (a DNase I inhibitor) addition to the medium significantly decreased the percentage of embryo expressing EGFP $(P<0.05)$. Nevertheless, both rates of cleavage and blastocyst formation were not statistically different from the control treatment $(P>0.05)$ (Fig. 1b).

\subsection{Assay of pattern of ooplasmic free calcium release}

The ICSI oocytes were co-incubation with Furo-3 $\left(5 \mu \mathrm{g} \cdot \mu \mathrm{L}^{-1}\right)$ for $30 \mathrm{~min}$, and then washed three times in H199. Free calcium in the ooplasm was checked directly in the culture dish under an inverted fluorescent microscope at $488 \mathrm{~nm}$ irradiation (IX70, Olympus, Japan). From immediately after ICSI, a 60-s video was taken and Nikon confocal analysis software EZ-C1-FreeViewerVer3.20-E used to create a chart. The $\mathrm{Ca}^{2+}$ release patterns after ICSI in different calcium concentrations medium are in Fig. 1c. The content of ooplasmic free $\mathrm{Ca}^{2+}$ did not

Table 1 Effects of $\mathrm{Ca}^{2+}$ concentration on ICSI embryos developmental competence and EGFP expression with/without electrical activation

\begin{tabular}{|c|c|c|c|c|c|}
\hline \multirow[b]{2}{*}{ Treatment } & \multirow{2}{*}{$\begin{array}{c}\mathrm{Ca}^{2+} \text { concentration } \\
/\left(\mathrm{mmol} \cdot \mathrm{L}^{-1}\right)\end{array}$} & \multicolumn{4}{|c|}{ No. } \\
\hline & & Injected oocytes & Cleavages $/ \%$ & Blastocysts $/ \%$ & $\begin{array}{c}\text { Embryos } \\
\text { expressing GFP/\% }\end{array}$ \\
\hline \multirow[t]{5}{*}{ Control } & 0 & 97 & $37.8 \pm 3.1^{\mathrm{d}}$ & $0.0 \pm 0.0^{\mathrm{a}}$ & $7.9 \pm 2.8^{\mathrm{b}}$ \\
\hline & 2 & 110 & $52.8 \pm 6.1^{\mathrm{c}}$ & $1.1 \pm 1.4^{\mathrm{a}}$ & $33.6 \pm 3.0^{\mathrm{a}}$ \\
\hline & 4 & 109 & $72.5 \pm 3.9^{\mathrm{ab}}$ & $0.0 \pm 0.0^{\mathrm{a}}$ & $48.2 \pm 10.2^{\mathrm{a}}$ \\
\hline & 6 & 96 & $79.3 \pm 8.4^{\mathrm{a}}$ & $0.0 \pm 0.0^{\mathrm{a}}$ & $43.6 \pm 8.2^{\mathrm{a}}$ \\
\hline & 8 & 95 & $62.8 \pm 4.1^{\mathrm{bc}}$ & $2.1 \pm 1.4^{\mathrm{a}}$ & $44.0 \pm 4.7^{\mathrm{a}}$ \\
\hline \multirow[t]{5}{*}{ Electrical activation } & 0 & 97 & $69.9 \pm 3.8^{\mathrm{a}}$ & $4.0 \pm 1.4^{\mathrm{a}}$ & $15.3 \pm 5.3^{\mathrm{b}}$ \\
\hline & 2 & 110 & $67.3 \pm 3.4^{\mathrm{a}}$ & $4.7 \pm 1.9^{\mathrm{a}}$ & $27.9 \pm 5.0^{\mathrm{ab}}$ \\
\hline & 4 & 115 & $77.0 \pm 3.2^{\mathrm{a}}$ & $8.1 \pm 3.2^{\mathrm{a}}$ & $45.4 \pm 6.2^{\mathrm{a}}$ \\
\hline & 6 & 108 & $78.6 \pm 1.3^{\mathrm{a}}$ & $8.4 \pm 6.0^{\mathrm{a}}$ & $42.2 \pm 10.7^{\mathrm{a}}$ \\
\hline & 8 & 108 & $71.6 \pm 1.3^{\mathrm{a}}$ & $10.9 \pm 6.0^{\mathrm{a}}$ & $40.5 \pm 7.7^{\mathrm{a}}$ \\
\hline
\end{tabular}

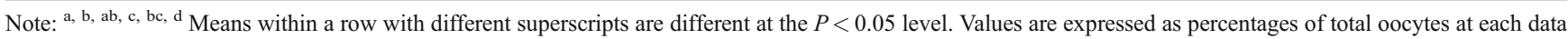
point investigated, the results with and without electrical activation were analysed separately. 

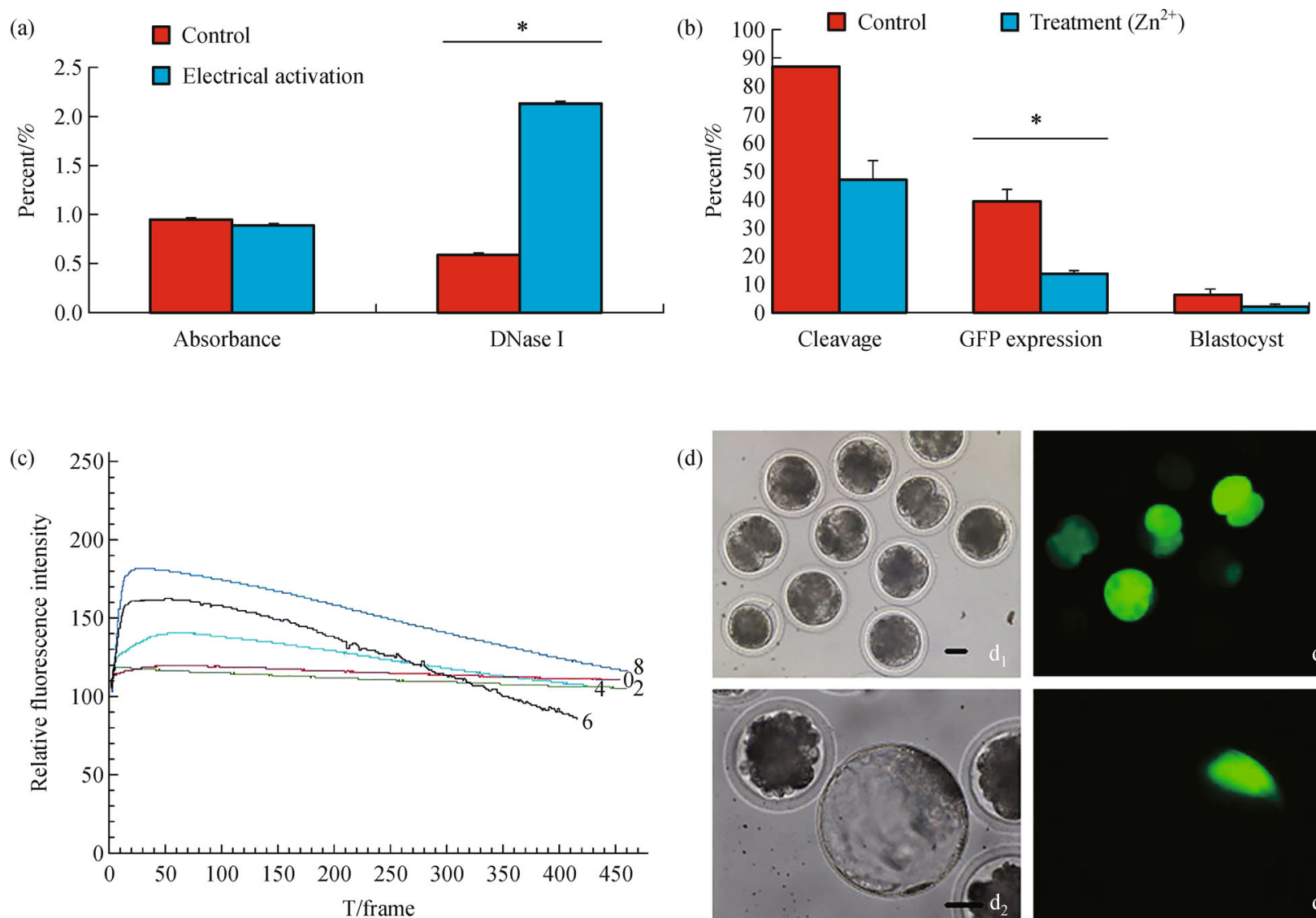

(d)
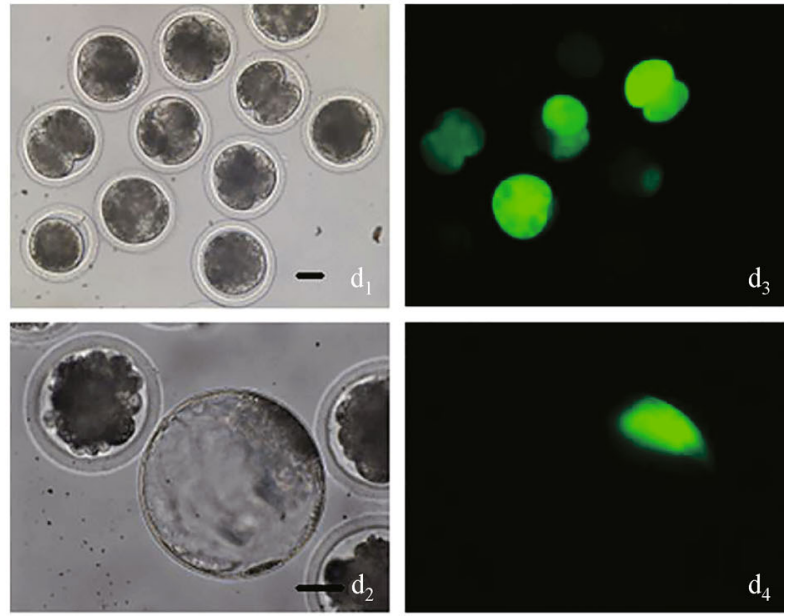

Fig. 1 DNase I activated by ooplasmic free $\mathrm{Ca}^{2+}$ affects expression of exogenous EGFP. (a) Comparison of DNase I activities in porcine oocytes with electrical stimulation. Electrically activated oocytes were used as the treatment group instead of ICSI treatment, the control was no electrical activation. Oocyte cytoplasm, methyl green and DNA were incubated, and absorbance were detected. DNase I activity was significantly increased after electrical activation. *, $P<0.05$; (b) effect of adding $2 \mathrm{mmol} \cdot \mathrm{L}^{-1} \mathrm{Zn}^{2+}$ to the manipulation medium on developmental competence and EGFP expression of ICSI embryos. ${ }^{*}, P<0.05$; (c) the $\mathrm{Ca}^{2+}$ release patterns after ICSI in different calcium concentrations medium. Abscissa is the time of calcium release, and ordinate is the relative fluorescence intensity. Calcium concentration in manipulation medium were $0,2,4,6,8 \mathrm{mmol} \cdot \mathrm{L}^{-1}$, respectively; (d) images of porcine embryos from IVM (in vitro maturation) oocytes injected with the frozen-thawed dead sperm exposed to pEGFP-N1 DNA. The porcine embryos under the microscopic white field at $48 \mathrm{~h}(\mathrm{~d} 1)$ and $168 \mathrm{~h}$ (d2) after ICSI; d3 and d4 represent the same embryos under the inverted fluorescent microscope after $488 \mathrm{~nm}$ irradiation. The embryos expressing EGFP sent out strong green light while the negative embryos were invisible. $\mathrm{Bar}=50 \mu \mathrm{m}$.

significantly change in $0 \mathrm{mmol} \cdot \mathrm{L}^{-1}$ group after ICSI, but the contents were significantly increased when $\mathrm{Ca}^{2+}$ was added to the media and the period of the release was about $8 \mathrm{~s}$. Figure 2 shows that ooplasmic free $\mathrm{Ca}^{2+}$ was released from the injection site and then gradually spread throughout the oocyte.

\section{Discussion}

Several techniques are currently used to produce transgenic mammalian embryos, including pronuclear microinjection ${ }^{[9]}, \mathrm{SCNT}^{[10]}$, sperm mediated gene transfer ${ }^{[11]}$ and intracytoplasmic sperm injection (ICSI)-mediatedgene transfer ${ }^{[12]}$. However, the mechanisms involved are not yet fully understood. ICSI involves mechanical transfer of a single sperm cell into the ooplasm. This procedure was first used in mammals in $1976^{[9]}$. The first critical step for stable transgenesis is introduction of exogenous DNA into the host genome. After transgene incorporation into a pronucleus, exogenous DNA can be integrated into the host genome mainly as result of the activity of DNA repair machinery associated with replication ${ }^{[10,11]}$. The early integration of the exogenous DNA into the host genome is a critical step for homogeneous transgenic embryo production, followed by parthenogenic activation ${ }^{[9-11]}$.

In the present study, the results indicate that $\mathrm{Ca}^{2+}$ concentration significantly affected the efficiency of ICSI embryos expressing EGFP regardless of electro-activation. Previous studies had indicated that ICSI-induced $\mathrm{Ca}^{2+}$ release was not equivalent to that initiated by IVF, especially with regards to its persistence ${ }^{[13]}$. Our results 

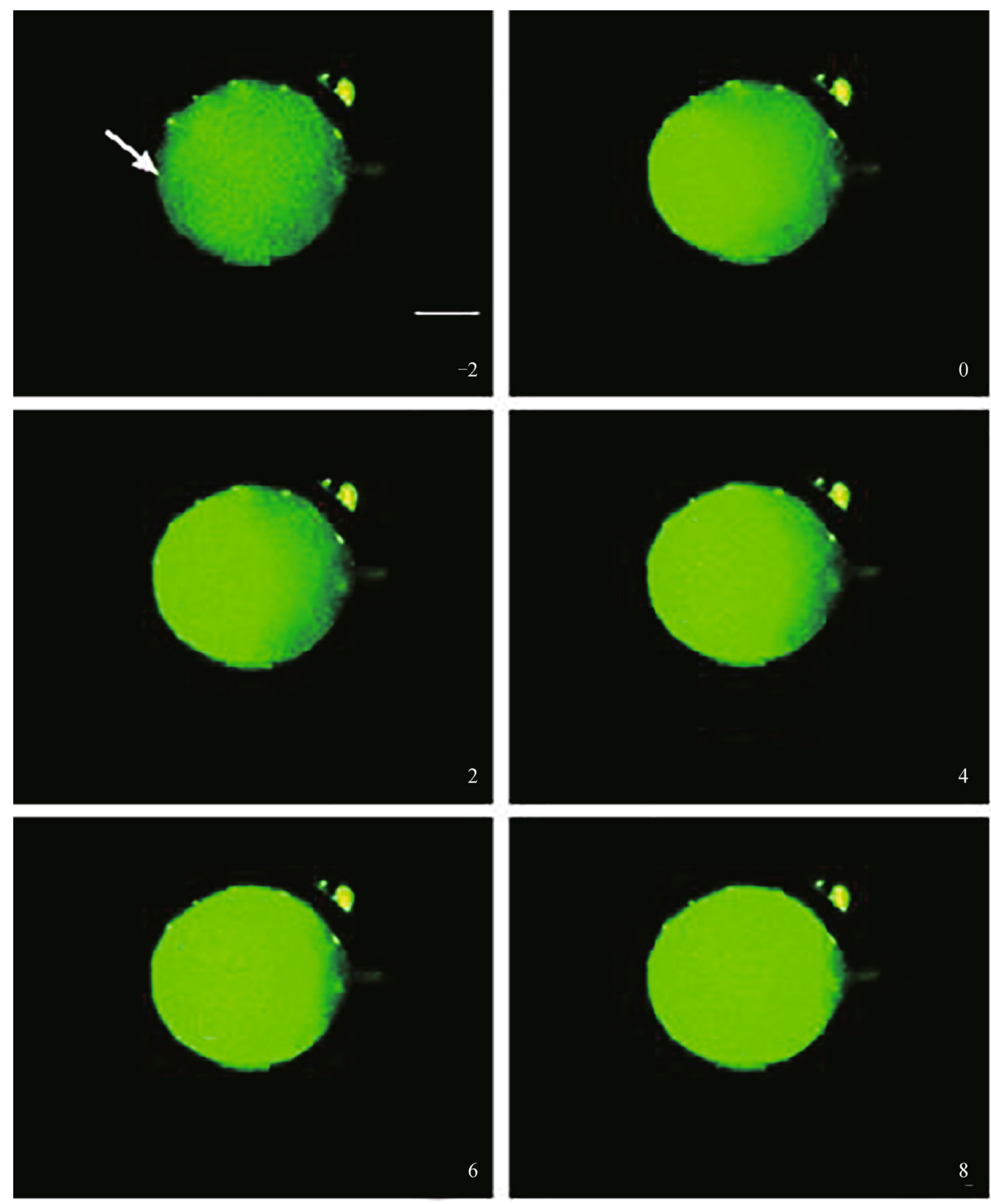

Fig. 2 The ooplasmic free $\mathrm{Ca}^{2+}$ content changes after ICSI. The oocytes were co-incubated with Furo- 3 for 30 min, injected in the culture dish under an inverted fluorescent microscope, and irradiated at $488 \mathrm{~nm}$. Images were taken from the movie of ICSI every $2 \mathrm{~s}$; the arrow indicates the ICSI site. $\mathrm{Bar}=50 \mu \mathrm{m}$.

confirmed ooplasmic free calcium release in ICSI oocytes was a single, long-lasting process rather than a reduplicate oscillation in natural fertilization, as suggested by Tesarik et al. ${ }^{[14]}$. The $\mathrm{Ca}^{2+}$ release occurred within $8 \mathrm{~s}$ after injection of frozen-thawed sperm. Furthermore, the $\mathrm{Ca}^{2+}$ release patterns in ICSI oocytes were related to the calcium concentrations in the manipulation media, and ooplasmic free $\mathrm{Ca}^{2+}$ contents were significantly increased with the augmentation of extracellular calcium. However, according to our results the ICSI oocytes rarely develop into blastocysts without an additional activation stimulus.
During normal fertilization, DNase I participates in conformational changes of paternal DNA during sperm remodeling, which could represent an important opportunity for exogenous DNA to be integrated into the zygote genome ${ }^{[15]}$. Moreover, the activity of DNase I was $\mathrm{Ca}^{2+}$ / $\mathrm{Mg}^{2+}$-dependent in pig MII matured oocytes ${ }^{[6]}$. Therefore, we proposed a hypothesis that free $\mathrm{Ca}^{2+}$ content in ooplasm is associated with the activity of DNase I. To verify this hypothesis, we first added $\mathrm{Zn}^{2+}$ which inhibited the activity of DNase I in the medium containing $\mathrm{Ca}^{2+}$, and found the rate of embryos expressing EGFP was 
significantly reduced. It is assumed that DNase I affected the efficiency of EGFP expression.

In this study, activity of DNase I in oocytes was detected immediately after electrical stimulation. About 45 oocytes synchronized for calcium release could be obtained with one treatment, but it was not possible to get the same number of ICSI oocytes within several seconds.

A previous study in our laboratory has documented that free calcium was released in ooplasm after electrical stimulation $^{[16]}$, and the release pattern was similar to that caused by mechanical injection in the present experiments. Our finding indicate that the activity of DNase $\mathrm{I}$ is positively related with free $\mathrm{Ca}^{2+}$ content in ooplasm. It is assumed that free $\mathrm{Ca}^{2+}$ release in ooplasm led to an increase of DNase I activity, which improved the efficiency of exogenous DNA expression. Notable, we showed that the efficiency of embryos expressing EGFP was significantly affected by $\mathrm{Ca}^{2+}$ concentrations in the manipulation media. It has shown that ooplasmic free calcium increase by mechanical injection was important for embryos to express EGFP. Nevertheless, the electro-activation administered to oocytes at more than $30 \mathrm{~min}$ after ICSI could not change the efficiency of embryos expressing EGFP, although the activation could significantly improve the developmental competence of ICSI oocytes. It is assumed that ooplasmic free $\mathrm{Ca}^{2+}$ content was necessary for exogenous DNA expression immediately after ICSI rather than 30 min later.

\section{Conclusions}

$\mathrm{Ca}^{2+}$ concentrations in manipulated media can affect the efficiency of EGFP expression by porcine ICSI embryos, and this was related to the activation of ooplasmic DNase I by free $\mathrm{Ca}^{2+}$ increase immediately after ICSI.

Acknowledgements This study was supported by the National Natural Science Foundation of China (30771548) and Beijing Natural Science Foundation (5072026). We greatly thank technical assistance provided by Wentao Zeng.

Compliance with ethics guidelines Shuaishuai Wu, Heng Chen, Yingzheng Wang, Hui Gao and Shenming Zeng declare that they have no conflict of interest or financial conflicts to disclose.

All applicable institutional and national guidelines for the care and use of animals were followed.

\section{References}

1. Nagashima H, Fujimura T, Takahagi Y, Kurome M, Wako N, Ochiai T, Esaki R, Kano K, Saito S, Okabe M, Murakami H. Development of efficient strategies for the production of genetically modified pigs. Theriogenology, 2003, 59(1): 95-106
2. Prather R S, Boice M L, Gibson J, Hoffman K E, Parry T W. In vitro development of embryos from Sinclair miniature pigs: a preliminary report. Theriogenology, 1995, 43(6): 1001-1007

3. The Sir Hans Krebs Lecture. 26th Meeting of the Federation of European Biochemical Societies (FEBS). Nice, France, June 19-24, 1999. Abstracts. Biochimie, 1999, 81(6 Suppl): S11-S454

4. Wu Y, Liu C J, Wan P C, Hao Z D, Zeng S M. Factors affecting the efficiency of producing porcine embryos expressing enhanced green fluorescence protein by ICSI-mediated gene transfer method. Animal Reproduction Science, 2009, 113(1-4): 156-166

5. Szczygiel M A, Moisyadi S, Ward W S. Expression of foreign DNA is associated with paternal chromosome degradation in intracytoplasmic sperm injection-mediated transgenesis in the mouse. Biology of Reproduction, 2003, 68(5): 1903-1910

6. Zannoni A, Spinaci M, Bernardini C, Bacci M L, Seren E, Mattioli M, Forni M. DNase I activity in pig MII oocytes: implications in transgenesis. Reproduction, 2006, 131(3): 461-468

7. Wu Y, Liu C J, Wan P C, Hao Z D, Zeng S M. Factors affecting the efficiency of producing porcine embryos expressing enhanced green fluorescence protein by ICSI-mediated gene transfer method. Animal Reproduction Science, 2009, 113(1-4): 156-166

8. Yoshida N, Perry A C. Piezo-actuated mouse intracytoplasmic sperm injection (ICSI). Nature Protocols, 2007, 2(2): 296-304

9. Liu C, Xie W, Gui C, Du Y. Pronuclear microinjection and oviduct transfer procedures for transgenic mouse production. Methods in Molecular Biology, 2013, 1027: 217-232

10. Song Y, Hai T, Wang Y, Guo R, Li W, Wang L, Zhou Q. Epigenetic reprogramming, gene expression and in vitro development of porcine SCNT embryos are significantly improved by a histone deacetylase inhibitor - m-carboxycinnamic acid bishydroxamide (CBHA). Protein \& Cell, 2014, 5(5): 382-393

11. Li F, Li L, Zhong Y, Xie Q, Huang J, Kang X, Wang D, Xu L, Huang T. Relationship between LTR methylation and gag expression of HIV-1 in human spermatozoa and sperm-derived embryos. PLoS ONE, 2013, 8(1): e54801

12. Moisyadi S, Kaminski J M, Yanagimachi R. Use of intracytoplasmic sperm injection (ICSI) to generate transgenic animals. Comparative Immunology, Microbiology and Infectious Diseases, 2009, 32(2): $47-60$

13. Kurokawa M, Fissore R A. ICSI-generated mouse zygotes exhibit altered calcium oscillations, inositol 1,4,5-trisphosphate receptor-1 down-regulation, and embryo development. Molecular Human Reproduction, 2003, 9(9): 523-533

14. Tesarik J. Oscillin-reopening the hunting season. Molecular Human Reproduction, 1998, 4(11): 1007-1009

15. Borini A, Tarozzi N, Bizzaro D, Bonu M A, Fava L, Flamigni C, Coticchio G. Sperm DNA fragmentation: paternal effect on early post-implantation embryo development in ART. Human Reproduction, 2006, 21(11): 2876-2881

16. Hao Z D, Liu S, Wu Y, Wan P C, Cui M S, Chen H, Zeng S M. Abnormal changes in mitochondria, lipid droplets, ATP and glutathione content, and $\mathrm{Ca}^{2+}$ release after electro-activation contribute to poor developmental competence of porcine oocyte during in vitro ageing. Reproduction, Fertility, and Development, 2009, 21(2): 323-332 